\title{
Portfolio Selection by the Axiom of Choice: Post Mean-Variance Analysis
}

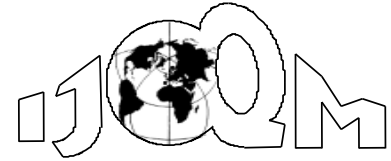

DOI: $10.46970 / 2020.26 .4 .4$

Volume 26, Number 4

December 2020, pp.303-318

\author{
K. Paul Yoon \\ Mohammad Sedaghat \\ Fairleigh Dickinson University \\ (yoon@fdu.edu) \\ (sedaghat@fdu.edu)
}

\author{
Gyutai Kim \\ Chosun University \\ (gtkim@Chosun.ac.kr)
}

\begin{abstract}
Markowitz's proposition on the mean-variance efficient frontier laid the foundation for the modern portfolio evaluation theory. However, we cannot select the optimal portfolio from a pool of efficient portfolios unless an investor formulates an appropriate utility function. Utility functions are difficult even for experts to construct. Instead, we offer an alternative approach by creating a quasi-utility function according to the axiom of choice. This quasi-utility approach has a clear choice rationale that investors can comprehend easily, and asks for a very light computation burden. We illustrate two cases to demonstrate how closely the quasi-utility reflects an investor's attitude towards risk. The results are further contrasted with the traditional risk-adjusted performance measures to show the efficacy of the proposed approach.
\end{abstract}

Keywords: Portfolio Performance Evaluation, Mean-Variance Efficient, CAPM, Axiom Of Choice, Quasi-Utility Function

\section{Introduction}

There exist very few investment options, especially in securities, without risk. However, investors' dream is to maximize return and minimize risk simultaneously. Markowitz $(1952,1959)$ showed that it is an impossible dream, and suggested to consider the mean-variance efficient portfolios. That is, to take portfolios that provide the highest return for a given risk or the lowest risk for a given return. Nevertheless, there remain many efficient portfolios. How do investors choose superior ones from the pool of efficient portfolios?

The Markowitz mean-variance efficient frontier is the standard theoretical model of normative investment behavior. Most modern textbooks consider the mean-varinace efficiency the method of choice for optimal portfolio construction and a means for rationalizing the value of diversification (Michaud, 1989). Over the last two decades, researchers have rendered comprehensive literature reviews on the Markowitz meanvariance model. Refer to Elton and Gruber (1997) ) and Kolm et al.(2014) for historical perspectives; Detemple (2014) and Zhang et al. (2018) for theoretical and empirical studies; Kalayci et al. (2019) for most recent developments and future studies in this field; Fabozzi et al. (2002) and Mangram (2013) for tutorial reviews.

Among recent post Markowitz's mean-variance analyses, two of the more prominent approaches for the operations research community are: Data Envelopment Analysis (DEA) and Generalized Sharpe Ratio (GSR). The DEA is a nonparametric 
method in operations research for the estimation of production frontiers (Charnes et al., 1978) that is often used in the performance evaluation of portfolios. For example, Liu et al. (2015) utilized DEA to estimate portfolio efficiency. The GSR was introduced by Hodges (1998). Later Zakamouline and Koekebakker (2009) presented two methods for the practical estimation of the GSR.

The Markowitz mean-varicance efficiency has also provided basis for Sharpe's Capital Asset Pricing Model (CAPM) on the theory of financial asset price formation (Sharpe, 1964; Fama and French, 2004). The CAPM, which defines the relationship between risk and return, formulates equations that quantify performance measures of securities. Three of the most widely used risk-adjusted performance measures are: Treynor index (Treynor, 1965) for the excess return against the systematic risk; Sharpe index (Sharpe, 1966) against the total risk; Jensen's Alpha (Jensen, 1968) against the benchmark return.

These indexes are defined as functions of the difference between the asset return and risk-free return. The higher index is supposed to take the higher preference. Understandably, because of a difference in their underlying assumptions, the three indexes do not yield an identical value. But a nontrivial shortcoming of these indexes is that they leave no room to accommodate an investor's tendency toward the risk.

Markowitz mean-variance efficency model has two stages: (1) an algorithm to generate efficient portfolios from a pool of available securities, (2) selection of portfolio(s) that renders the maximun expected utilty. Model builders have utilized Gaussian or quadratic utility functions. Recently Markowitz (2014) proved that a wide variety of concave (risk-averse) funtions can be utilized. However, even for experts, it is difficult to construct a proper utilty function. Instead, we suggest an alternative approach that is consistent with the axiom of (rational) choice, which stipulates that individuals will prefer an alternative that is closest to the verybest alternative and furthest from the veryworst alternative.

The goal of this paper is to provide a simple framework to rank portfolios on the mean-variance efficient frontier which does not rely on (complex) utility maximization. Here the utility maximization is to be accomplished by a quantitative execution of the axiom of rational choice.

The remainder of this paper is organized as follows: Section 2 reviews the wellknown mean-variance efficient frontier and illustrates how an investor's attitudes towards risk should yield a different portfolio selection. Section 3 conceives a global utility function with mean return and variance of a portfolio. Section 4 develops the quasi-utility function based upon the axiom of rational choice. Section 5 formulates the computation steps of the quasi-utility function. Section 6 demonstrates the execution of the quasi-utility function using two cases from finance textbooks. Finally, Section 7 offers concluding remarks on our pragmatic approach and identifies the future research topics.

\section{Choosing from Efficient Portfolios}

Historical evidence supports the underlying premise of a positive relationship between risk and return. Therefore, it's a rare event for investors to capture a security with higher return and lower risk. The bottom line is to avoid a security with low return and high risk. Traditionally, financial analysis has used the mean return and variance (or standard deviation) of a portfolio to measure its investment value in the market. 
Let $R_{i}$ and $S_{i}$ represent the mean return and standard deviation, respectively, of portfolio $A_{i}$. Then, portfolio $A_{i}$ may be denoted as

$A_{i}=\left(S_{i}, R_{i}\right), \quad i=1, \ldots m$

Portfolio $A_{j}$ is judged to dominate portfolio $A_{k}$ when one of the stochastic dominance rules is satistified: (1) $R_{j}>R_{k}$ and $S_{j}<S_{k}$, or (2) $R_{j}>R_{k}$ and $S_{j}=S_{k}$, or (3) $R_{j}=R_{k}$ and $S_{j}<S_{k}$. Otherwise, $A_{j}$ and $A_{k}$ do not dominate each other. Figure 1 shows the location of five portfolios. First, any portfolios that are located in the shaded area dominate portfolio $\boldsymbol{C}$. Next, four portfolios $(\boldsymbol{A}, \boldsymbol{B}, \boldsymbol{D}, \boldsymbol{E})$ do not dominate each other. As elucidated by Markowitz (1952), such a collection of non-dominated portfolio defines the mean-variance efficient frontier, which is marked with a solid line in Figure 1.

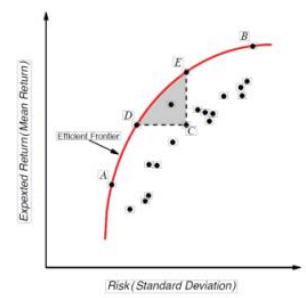

Figure 1 Mean-Variance Efficient Frontier

Now, can we prioritize efficient portfolios, for example, between $\boldsymbol{A}$ and $\boldsymbol{B}$ ? Those who are risk averse would tend to concentrate on their choices closer to a portfolio (such as $\boldsymbol{A}$ ) that has minimum risk. In contrast, risk seekers are likely to opt for a portfolio (like $\boldsymbol{B}$ ) that offers the highest return. What about efficient portfolios $\boldsymbol{D}$ and $\boldsymbol{E}$ that have medium risk and medium return? It is difficult to determine which one of these may be more preferable unless the investor's utility function is known.

\section{Forming Global Utility Function}

The CAPM indexes are defined as functions of the difference between the asset return and risk-free return. The higher index is supposed to take the higher preference. But these indexes have no mechanism to accommodate an investor's tendency toward the risk. Instead, we create a (utility) function of the ratio of return to risk so that an investor can express the relative importance between return and risk.

Theoretically, we need to build a bivariate utility function with return and variance. Even the construction of a single variable utility function is not an easy task, and then it is a daunting task for investors to build a bivariate utility function (Keeney and Raiffa, 1976). Hence, we consider a global utility function in which the marginal rate of substitution remains unchanged throughout the feasible domain.

Since we want to simultaneously maximize mean return $(\mathrm{R})$ and minimize standard deviation (S). A global utility function can be defined as

$V=\frac{R}{S}$ 
Equation (2) can be rewritten by

$R=V \cdot S$

When we plot Equation (3) in the $(S, R)$ space, it forms a straight line that has a slope of $V$ and y-axis intercept of zero. Any portfolios that are located on the same line should, in theory at least, have the equal preference. This line is called as an indifference line (or curve). As the value increases, the indifference line becomes steeper. Then the most preferred portfolios are the portfolios that meet the indifference line with the steepest slope.

As we have seen in Figure 1, varying weights on return and risk should reflect an investor's attitude toward risk. When an investor is more (less) risk averse, s/he will put more (less) weights on the risk and less (more) on the return. Let's denote $w_{1}$ be a weight for the standard deviation and $w_{2}$ be a weight for the mean return, where $0 \leq$ $w_{1} \leq 1,0 \leq w_{2} \leq 1$, and $w_{1}+w_{2}=1$. When the investor has a more risk averse attitude, the correspoding weights should be $w_{1}>w_{2}$. Similarly, weights are to be $w_{1}<w_{2}$ under the less risk averse (i.e., risk seeking) policy. And the weights are equal $\left(w_{1}=w_{2}\right)$ under the risk neutral policy.

How do we implement the weights in the global utility function? Even though we put different weights on the global utility function like $w_{2} \cdot R / w_{1} \cdot S$, it does not alter preference rankings because all portfolio values are automatically changed by $w_{2} / w_{1}$. In other words, the global utility function cannot accommodate the investor's risk averse or risk seeking attitudes. We construct a quasi-utility function that accepts weights on risk and return in the next section.

\section{Building Quasi-Utility Function}

We all perceive that ideals are often unattainable or infeasible. However, they work as major guiding posts or reference points in human choice and preferences. Dember and Earl (1957) first proposed the concept of an ideal point as the peak of a single-peaked function in the motivation theories. Coombs (1964) demonstrated that there is an ideal level of attributes for objectives of choice that the decision maker's utilities decease monotonically on both sides of the ideal point.

Ideal point models in marketing research are spatial models in which the preference of a consumer for a product is an inverse function of distance between the point that represents the product and the ideal points that represent the consumer. Ideal point models possess an intuitive appeal which has contribututed to thier widespread acceptance by those modelling consumer behavior (Huber, 1976; Kamakura and Srivastava, 1986; Mackay et al., 1995).

Decision scientists adopted the concept of Ideal point in the multiple criteria decision analyses (Yu, 1973; Hall, 1989). Zeleny (1982) postulated the axiom of choice: alternatives that are closer to the ideal are preferred to those that are farther away. To be as close as possible to the perecived ideal is the rationale of human choice.

Carroll (1972) first introduced the interesting concept of the anti-ideal (i.e., worst) point, which is comprised of the worst ratings only. Since the anti-ideal point is opposite to the ideal point, it is natural that humans desire to choose the object that is as far as possible from the anti-ideal point. Indeed, several decision scientists have 
utilized the anti-ideal point in their analyses (Hwang and Yoon, 1981; Zeleny, 1982; Michalowski, 1988; Michalowski and Szapiro, 1989; Shen et al., 2016). Unfortunately, the choices that are based on ideal and anti-ideal points are not often identical. We like to utilize both of them simultaneously rather than debate which is more legitimate.

Let us imagine an artificial portfolio that is composed of the maximum return and the minimum risk that are taken from the existing portfolios, and call it an ideal portfolio $\left(A^{+}\right)$. Similarly, we create an anti-ideal portfolio $\left(A^{-}\right)$that is composed of the minimum return and maximum risk. Both ideal and anti-ideal portfolios are usually infeasible, but works as potential choice reference points. Then, we can measure distances between portfolio $A_{i}$ and $A^{+}$, denoted by $D_{i}^{+}$, and between portfolio $A_{i}$ and $A^{-}$, denoted as $D_{i}^{-}$. Accordingly, portfolio $A_{i}$ may be defined as

$A_{i}=\left(D_{i}^{+}, D_{i}^{-}\right), i=1, \ldots, m$

Figure 2 depicts the Euclidean distances to ideal and anti-ideal points graphically.

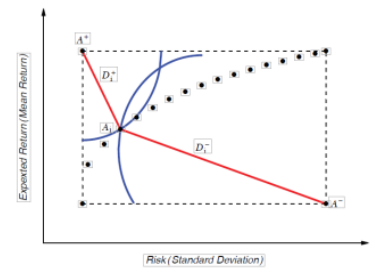

Figure 2 Euclidean Distances to Ideal and Anti-Ideal Portfolios

Since we want to maximize the distance from anti-ideal portfolio $\left(D^{-}\right)$and minimize the distance from the ideal porrfolio $\left(D^{+}\right)$simultaneously, a quasi-utility function of portfolios can be formulated by

$V=\frac{D^{-}}{D^{+}}$

Equation (5) can be rewritten by

$D^{-}=V \cdot D^{+}$

Comparing Equations (3) and (6) reveals a striking similarity between them: $R$ is replaced by $D^{-}$and $S$ is replaced by $D^{+}$. Following the same logic, the most preferred portfolio meets the indifference line that has the steepest slope in the $\left(D^{+}, D^{-}\right)$space.

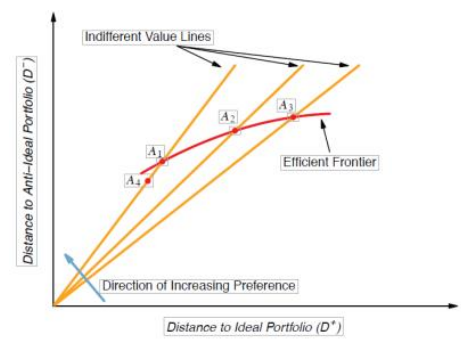

Figure 3 Preference Order by Quasi-Utility Function 
Figure 3 shows that both portfolios $\boldsymbol{A}_{\mathbf{1}}$ and $\boldsymbol{A}_{\mathbf{4}}$ are tied for the most preferred, $\boldsymbol{A}_{\mathbf{2}}$ is the next, and $\boldsymbol{A}_{3}$ is the least preferred portfolio. These relationships are concisely written as $\boldsymbol{A}_{1} \sim \boldsymbol{A}_{\mathbf{4}}>\boldsymbol{A}_{\mathbf{2}}>\boldsymbol{A}_{3}$.

\section{Implementing Quasi-Utility Function}

How can we incorporate different weights on risk and return into the quasi-utility function? First, we need a comparable scale because they may possess incomparable magnitudes or units. We use the vector normalization to ensure that the sum of each ratings always yields a unit vector. Subsequently, we may apply the weights on standard deviation and return.

A portfolio that is expressed by the weighted comparable ratings is denoted as

$A_{i}=\left(s_{i}, r_{i}\right), \quad i=1, \ldots, m$

$$
\text { Where } \begin{aligned}
s_{i} & =w_{1} \cdot \frac{s_{i}}{\sqrt{\sum_{i=1}^{m} s_{i}^{2}}} \\
r_{i} & =w_{2} \cdot \frac{R_{i}}{\sqrt{\sum_{i=1}^{m} R_{i}^{2}}}
\end{aligned}
$$

By the definition of the ideal and anti-ideal portfolios, they can be identified in the weighted comparable space

$$
\begin{aligned}
& A^{+}=\left(s^{+}, r^{+}\right)=\left(\min _{i} s_{i}, \max _{i} r_{i}\right) \\
& A^{-}=\left(s^{-}, r^{-}\right)=\left(\max _{i} s_{i}, \min _{i} r_{i}\right)
\end{aligned}
$$

It is noted that the ideal and anti-ideal portfolios are artificial, infeasible portfolios, and their creations are functions of all portfolios under consideration, and of particular combinations of weights.

Among the distance measures, we choose the Euclidean distance because it is the ordinary straight-line distance between two points. The weighted Euclidean distances to ideal and anti-ideal portfolios can be computed by

$$
\begin{array}{ll}
D_{i}^{+}=\sqrt{\left(s_{i}-s^{+}\right)^{2}+\left(r_{i}-r^{+}\right)^{2}}, & i=1, \ldots, m \\
D_{i}^{-}=\sqrt{\left(s_{i}-s^{-}\right)^{2}+\left(r_{i}-r^{-}\right)^{2}}, & i=1, \ldots, m
\end{array}
$$

Finally, the value of each portfolio is given by

$$
V_{i}=\frac{D_{i}^{-}}{D_{i}^{+}}, i=1, \ldots, m
$$

Now, an investor can select a portfolio with the maximum $V_{i}$ or rank portfolios according to $V_{i}$ in the descending order. 


\section{Illustrating Mutual Funds Selection}

Two cases from finance textbooks are illustrated to show the efficacy of the quasiutility method. The first case is aimed at how accurately the quasi-utility reflects the investor's varying attitudes towards the risk. The second case is to observe how closely quasi-utility resembles the traditional risk-adjusted performance measures such as Treynor, Sharpe and Jensen's alpha.

\subsection{Ten Stock Mutual Funds}

We have argued that the quasi-utility function could be a reasonable substitute for an investor's real utility function. In order to see how closely the quasi-utility reflects the decision makers' varying risk attitudes, we take the data from Hearth and Zaima (2004), which was also adopted by Yoon and Kim (2017). Table 1 lists 10 stock mutual funds along with their mean returns and standard deviation. Figure 4 shows locations of 10 funds in the $(S, R)$ space. All funds lie on the efficient frontier because funds with higher returns also have a higher standard deviation. Next, we make the preference orders among the efficient frontiers using the quasi-utility function.

Table 1 Ten Funds in Return and Risk (Hearth and Zaima, 2004)

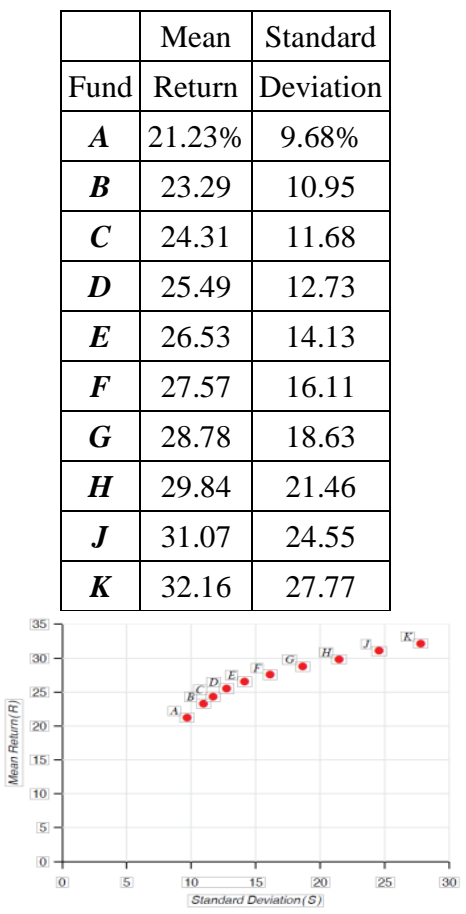

Figure 4 Ten Mutual Funds in (S, R) Space

We derived the quasi-utility analysis under three scenarios from risk seeking to risk averse policies. Figure 5 shows the scatterplot of 10 funds in the $\left(D^{+}, D^{-}\right)$space when the investor has a risk seeking attitude (say, $\left.w_{1}=0.3, w_{2}=0.7\right)$. Six funds $(\boldsymbol{A}, \boldsymbol{B}, \boldsymbol{C}$, $\boldsymbol{D}, \boldsymbol{E}, \boldsymbol{F})$ are located on the efficient frontier. We notice that funds with relatively larger 
variances like $(\boldsymbol{E}, \boldsymbol{F})$ became efficient fund due to the risk seeking propensity. Fund $\boldsymbol{E}$ is the opimal fund because it is located on the indifference line with the steepest slope, which is simliar to $\boldsymbol{A}_{\mathbf{1}}$ or $\boldsymbol{A}_{\mathbf{4}}$ in Figure 3.

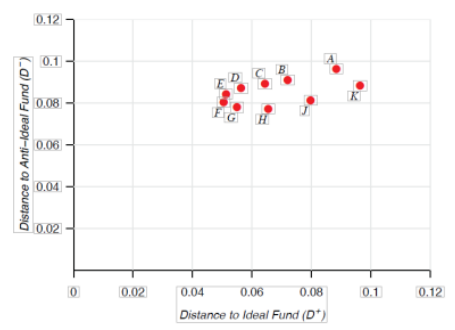

Figure 5 Ten Mutual Funds with $\left(w_{1}, w_{2}\right)=(0.3,0.7)$ in $\left(D^{+}, D^{-)}\right.$Space

Figure 6 shows four funds $(\boldsymbol{A}, \boldsymbol{B}, \boldsymbol{C}, \boldsymbol{D})$ that are located on the efficient frontier under the risk neutral position on the risk $\left(w_{1}=0.5, w_{2}=0.5\right)$. Fund $\boldsymbol{C}$, which is on the steepest indifference line, is the optimal fund. Figure 7 shows the locations of funds when the investor has a risk averse attitude $\left(w_{1}=0.7, w_{2}=0.3\right)$. This time around, only two funds $(\boldsymbol{A}, \boldsymbol{B})$ remained on the efficient frontier while dropping funds with larger variances $(\boldsymbol{C}, \boldsymbol{D})$. Fund $\boldsymbol{B}$ happens to be the optimal fund.

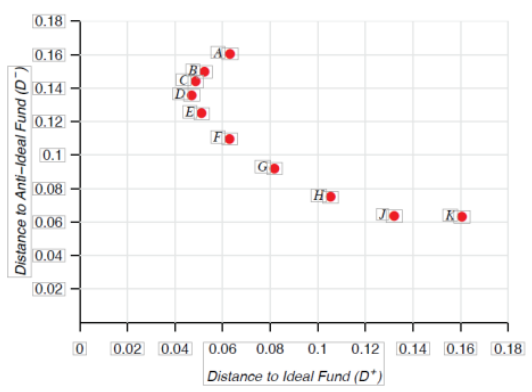

Figure 6 Ten Mutual Funds with $\left(w_{1}, w_{2}\right)=(0.5,0.5)$ in $\left(D^{+}, D^{-)}\right.$Space

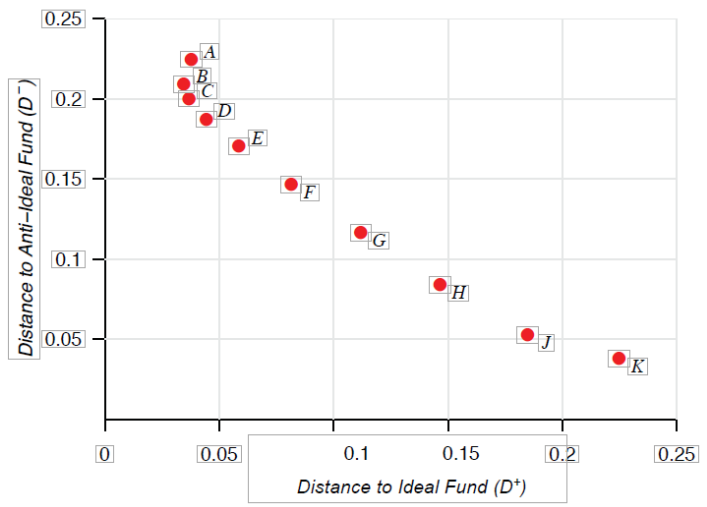

Figure 7 Ten Mutual Funds with $\left(w_{1}, w_{2}\right)=(0.7,0.3)$ in $\left(D^{+}, D^{-)}\right.$Space 
Table 2 lists the quasi-utilities (i.e., $V$ values) and the complete rankings of 10 funds under three scenarios. Under the risk neutral attitude, fund $\boldsymbol{C}$ (with medium return and medium risk) captures the first rank. Under the risk seeking, fund $\boldsymbol{E}$ (with larger return and larger risk) gets the first rank. Under risk averse attitude, fund $\boldsymbol{B}$ (with smaller return and smaller risk) earns the top rank. Two funds $(\boldsymbol{J}, \boldsymbol{K})$ remain at the bottom rank under all situations. It is interesting to see that the investor's risk attitudes are supposedly reflected in the preference ranking of funds.

Table 2 Quasi-Utility Values under Different Weights

\begin{tabular}{|c|c|c|c|c|c|c|c|c|c|c|c|c|}
\hline (w1, w2 $)$ & \multicolumn{4}{|c|}{$(\mathbf{0 . 3}, \mathbf{0 . 7})$} & \multicolumn{4}{c|}{$\mathbf{( 0 . 5 , 0 . 5})$} & \multicolumn{4}{c|}{$(\mathbf{0 . 7 , 0 . 3})$} \\
\hline Fund & D+ & D- & V & Rank & D+ & D- & V & Rank & D+ & D- & V & Rank \\
\hline A & 0.0883 & 0.0963 & 1.0905 & 8 & 0.0631 & 0.1606 & 2.5446 & 4 & 0.0379 & 0.2248 & 5.9375 & 2 \\
\hline B & 0.0720 & 0.0911 & 1.2653 & 6 & 0.0524 & 0.1498 & 2.8563 & 3 & 0.0345 & 0.2091 & 6.0547 & 1 \\
\hline C & 0.0643 & 0.0892 & 1.3870 & 5 & 0.0487 & 0.1439 & 2.9568 & 1 & 0.0368 & 0.2002 & 5.4353 & 3 \\
\hline D & 0.0563 & 0.0872 & 1.5484 & 3 & 0.0471 & 0.1357 & 2.8838 & 2 & 0.0444 & 0.1875 & 4.2236 & 4 \\
\hline E & 0.0513 & 0.0843 & 1.6437 & 1 & 0.0512 & 0.1249 & 2.4412 & 5 & 0.0586 & 0.1705 & 2.9076 & 5 \\
\hline F & 0.0505 & 0.0805 & 1.5947 & 2 & 0.0629 & 0.1098 & 1.7446 & 6 & 0.0815 & 0.1466 & 1.7988 & 6 \\
\hline G & 0.0549 & 0.0781 & 1.4209 & 4 & 0.0818 & 0.0921 & 1.1258 & 7 & 0.1118 & 0.1166 & 1.0422 & 7 \\
\hline H & 0.0655 & 0.0773 & 1.1802 & 7 & 0.1054 & 0.0749 & 0.7104 & 8 & 0.1466 & 0.0839 & 0.5722 & 8 \\
\hline J & 0.0797 & 0.0814 & 1.0211 & 9 & 0.1321 & 0.0636 & 0.4813 & 9 & 0.1848 & 0.0526 & 0.2844 & 9 \\
\hline K & 0.0963 & 0.0883 & 0.9170 & 10 & 0.1606 & 0.0631 & 0.3930 & 10 & 0.2248 & 0.0379 & 0.1684 & 10 \\
\hline
\end{tabular}

\subsection{Thirty Mutual Funds}

In order to compare with the risk-adjusted performance measures, we analyzed the data from Reilly and Brown (2006). Table 3 lists 30 open-end mutual funds along with their mean returns and standard deviation. In addition, it includes well-established performance measures.

Table 3 Performance Measures for 30 Mutual Funds (Reilly and Brown,2006)

\begin{tabular}{|c|c|c|c|c|c|c|c|c|}
\hline Fund & Mean & Standard & \multicolumn{2}{|c|}{ Treynor } & \multicolumn{2}{|c|}{ Sharpe } & \multicolumn{2}{|c|}{ Jensen (1 Factor) } \\
\hline Ticker & Return & Deviation & Value & Rank & Value & Rank & Value & Rank \\
\hline$A G$ & -3.67 & 21.12 & -5.865 & 29 & -0.316 & 29 & -0.22 & 29 \\
\hline$A S$ & 17.33 & 15.65 & 22.369 & 3 & 0.914 & 3 & 1.381 & 3 \\
\hline$B \boldsymbol{B}$ & 22.98 & 24.93 & 21.479 & 4 & 0.8 & 4 & 1.939 & 1 \\
\hline $\mathrm{CO}$ & 6.42 & 28.06 & 3.334 & 19 & 0.121 & 22 & 0.584 & 19 \\
\hline$C S$ & 0.93 & 24.51 & -1.725 & 25 & -0.086 & 26 & 0.186 & 23 \\
\hline$\overline{D A}$ & -0.09 & 13.47 & -4.299 & 27 & -0.231 & 27 & -0.045 & 27 \\
\hline$F M$ & -1.8 & 16.97 & -4.835 & 28 & -0.284 & 28 & -0.106 & 28 \\
\hline$G C$ & 11.46 & 15.09 & 14.54 & 6 & 0.558 & 8 & 0.874 & 11 \\
\hline$H W$ & 9.26 & 17.34 & 8.507 & 13 & 0.359 & 13 & 0.736 & 13 \\
\hline$J A$ & -4.52 & 23.1 & -6.691 & 30 & -0.327 & 30 & -0.294 & 30 \\
\hline$K D$ & 5.96 & 18.14 & 4.176 & 17 & 0.162 & 18 & 0.452 & 21 \\
\hline$K S$ & -0.2 & 37.96 & \begin{tabular}{|l|}
-2.379 \\
\end{tabular} & 26 & -0.085 & 25 & 0.133 & 26 \\
\hline$L Z$ & 10.79 & 16.16 & 10.033 & 10 & 0.481 & 9 & 0.877 & 10 \\
\hline$M C$ & 4.42 & 4.34 & 1.756 & 22 & 0.321 & 14 & 0.627 & 16 \\
\hline
\end{tabular}




\begin{tabular}{|c|c|c|c|c|c|c|c|c|}
\hline $\boldsymbol{M G}$ & 14.94 & 18.74 & 13.522 & 8 & 0.636 & 7 & 1.254 & 4 \\
\hline $\boldsymbol{N I}$ & 7.01 & 17.53 & 4.555 & 16 & 0.227 & 17 & 0.591 & 18 \\
\hline $\boldsymbol{N P}$ & 1.64 & 17.95 & -1.416 & 24 & -0.077 & 24 & 0.174 & 24 \\
\hline $\boldsymbol{N} \boldsymbol{V}$ & 14.43 & 17.27 & 14.043 & 7 & 0.66 & 6 & 1.191 & 6 \\
\hline $\boldsymbol{P D}$ & 13.05 & 21.14 & 10.502 & 9 & 0.474 & 10 & 1.119 & 8 \\
\hline $\boldsymbol{P G}$ & 8.44 & 22.26 & 6.436 & 14 & 0.243 & 15 & 0.701 & 14 \\
\hline $\boldsymbol{P R}$ & 15.8 & 13.58 & 24.658 & 2 & 0.941 & 2 & 1.218 & 5 \\
\hline $\boldsymbol{R S}$ & 21.38 & 17.61 & 30.816 & 1 & 1.043 & 1 & 1.706 & 2 \\
\hline $\boldsymbol{R} \boldsymbol{Y}$ & 14.43 & 15.41 & 16.264 & 5 & 0.74 & 5 & 1.158 & 7 \\
\hline $\boldsymbol{S L}$ & 7.26 & 18.12 & 4.87 & 15 & 0.233 & 16 & 0.61 & 17 \\
\hline $\boldsymbol{S S}$ & 11.3 & 19.97 & 9.277 & 11 & 0.415 & 12 & 0.954 & 9 \\
\hline $\boldsymbol{T G}$ & 5.44 & 16.9 & 2.875 & 21 & 0.143 & 20 & 0.451 & 22 \\
\hline $\boldsymbol{T W}$ & 3.21 & 12.01 & 0.371 & 23 & 0.015 & 23 & 0.162 & 25 \\
\hline $\boldsymbol{V G}$ & 6.88 & 27.27 & 3.527 & 18 & 0.141 & 21 & 0.644 & 15 \\
\hline $\boldsymbol{V P}$ & 6.23 & 20.67 & 3.041 & 20 & 0.155 & 19 & 0.578 & 20 \\
\hline $\boldsymbol{V S}$ & 10.44 & 16.42 & 8.858 & 12 & 0.451 & 11 & 0.866 & 12 \\
\hline
\end{tabular}

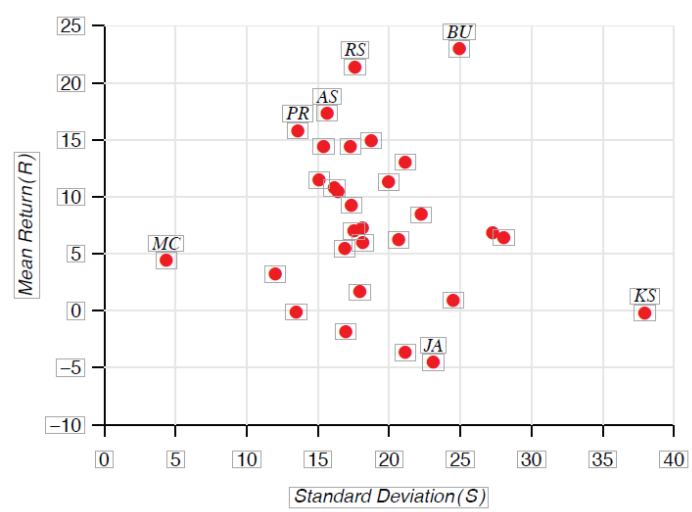

Figure 8 Thirty Mutual Funds in (S, R) Space

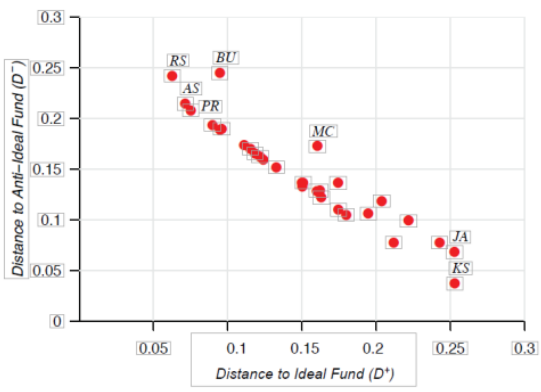

Figure 9 Thirty Mutual Funds with $\left(w_{1}, w_{2}\right)=(0.5,0.5)$ in $\left(D^{+}, D^{-)}\right.$Space

Figure 8 shows the scatterplot of 30 mutual funds in the $(S, R)$ space. We see five funds $(\boldsymbol{M C}, \boldsymbol{P R}, \mathbf{A S}, \boldsymbol{R S}, \boldsymbol{B} \boldsymbol{U})$ belong to the efficient frontier, and two funds $(\boldsymbol{J A}, \boldsymbol{K S})$ form the least preferred group. Figure 9 shows the scatterplot of these funds in the $\left(D^{+}, D^{-}\right)$space under neutrality. We can see that fund $\boldsymbol{R} \boldsymbol{S}$ dominates all other funds. 
The preference order of other conspicuous funds are $\mathbf{R S}>\mathbf{A S}>\mathbf{P R} \sim \mathbf{B U}>$ MC $>\cdots>$ JA $>$ KS.

It is interesting to contrast two scatter plots in Figure 8 and Figure 9. The scatter plot in Figure 8 forms a round shape whereas the scatter plot in Figure 9 forms a linear band. The narrower the band of scatter points is, the stronger dominance relationship exits among funds. In other words, the plot in $\left(D^{+}, D^{-}\right)$space offers more discriminatory power in funds evaluation than the plot in $(S, R)$ space.

Table 4 lists the prioritization of 30 funds under five scenarios from the risk seeking to the risk averse policies. Table 5 summarizes the top five funds. Under risk seeking and risk neutral attitude (i.e., $w_{1} \leq w_{2}$ ), fund $\boldsymbol{R S}$ with very high return captures the first rank. Fund $\boldsymbol{R S}$ is also the one that is ranked first by Treynor and Sharpe measures. Under risk averse, $\boldsymbol{P R}$ and $\boldsymbol{M C}$ with high return and low risk take the first rank. Fund $\boldsymbol{P R}$ seems to be resilient so that it remains within the top five under all scenarios.

Table 4 Performance Evaluation by Quasi-Utility Function

\begin{tabular}{|c|c|c|c|c|c|c|c|c|c|c|}
\hline$\left(w_{1}, w_{2}\right)$ & $(0.2,0.8)$ & \multicolumn{2}{|c|}{$(0.3,0.7)$} & \multicolumn{2}{c|}{$(0.5,0.5)$} & \multicolumn{2}{c|}{$(0.7,0.3)$} & \multicolumn{2}{c|}{$(0.8,0.2)$} \\
\hline Ticker & $\mathrm{V}$ & Rank & $\mathrm{V}$ & Rank & $\mathrm{V}$ & Rank & $\mathrm{V}$ & Rank & $\mathrm{V}$ & Rank \\
\hline $\boldsymbol{A G}$ & 0.0849 & 29 & 0.1466 & 29 & 0.3203 & 28 & 0.6181 & 25 & 0.8046 & 25 \\
\hline $\boldsymbol{A} \boldsymbol{S}$ & 3.7682 & 3 & 3.7597 & 3 & 3.0123 & 2 & 2.2964 & 2 & 2.1140 & 4 \\
\hline $\boldsymbol{B U}$ & 10.0555 & 2 & 6.8532 & 2 & 2.5883 & 4 & 1.2194 & 13 & 0.8912 & 23 \\
\hline $\boldsymbol{C O}$ & 0.6527 & 18 & 0.6484 & 20 & 0.5831 & 24 & 0.4707 & 29 & 0.4468 & 29 \\
\hline $\boldsymbol{C} \boldsymbol{S}$ & 0.2564 & 25 & 0.2792 & 26 & 0.3668 & 27 & 0.5191 & 26 & 0.6038 & 27 \\
\hline $\boldsymbol{D G}$ & 0.2346 & 26 & 0.3084 & 25 & 0.5839 & 23 & 1.1912 & 15 & 1.7344 & 9 \\
\hline $\boldsymbol{F M}$ & 0.1531 & 28 & 0.2213 & 27 & 0.4478 & 26 & 0.8911 & 23 & 1.2243 & 18 \\
\hline $\boldsymbol{G C}$ & 1.3992 & 9 & 1.4419 & 9 & 1.5617 & 8 & 1.8249 & 6 & 2.0000 & 6 \\
\hline $\boldsymbol{H W}$ & 1.0142 & 13 & 1.0466 & 13 & 1.1464 & 13 & 1.3540 & 12 & 1.4895 & 12 \\
\hline $\boldsymbol{J A}$ & 0.0667 & 30 & 0.1222 & 30 & 0.2703 & 29 & 0.5125 & 28 & 0.6524 & 26 \\
\hline $\boldsymbol{K D}$ & 0.6294 & 20 & 0.6636 & 19 & 0.8021 & 18 & 1.0942 & 20 & 1.2805 & 17 \\
\hline $\boldsymbol{K} \boldsymbol{S}$ & 0.1831 & 27 & 0.1784 & 28 & 0.1475 & 30 & 0.0727 & 30 & 0.0574 & 30 \\
\hline $\boldsymbol{L Z}$ & 1.2658 & 11 & 1.3025 & 11 & 1.4004 & 10 & 1.6086 & 8 & 1.7478 & 8 \\
\hline $\boldsymbol{M C}$ & 0.5354 & 22 & 0.6342 & 21 & 1.0776 & 14 & 2.2912 & 3 & 3.8859 & 1 \\
\hline $\boldsymbol{M G}$ & 2.3726 & 5 & 2.3586 & 5 & 1.9793 & 7 & 1.5437 & 10 & 1.4297 & 14 \\
\hline $\boldsymbol{N I}$ & 0.7354 & 16 & 0.7704 & 16 & 0.9085 & 16 & 1.2033 & 14 & 1.3929 & 15 \\
\hline $\boldsymbol{N P}$ & 0.3109 & 24 & 0.3569 & 24 & 0.5459 & 25 & 0.9334 & 21 & 1.1961 & 19 \\
\hline $\boldsymbol{N} \boldsymbol{V}$ & 2.1934 & 7 & 2.2064 & 7 & 1.9970 & 6 & 1.7277 & 7 & 1.6636 & 11 \\
\hline $\boldsymbol{P D}$ & 1.7385 & 8 & 1.7252 & 8 & 1.4758 & 9 & 1.1580 & 19 & 1.0746 & 21 \\
\hline $\boldsymbol{P G}$ & 0.8895 & 14 & 0.9001 & 14 & 0.8868 & 17 & 0.8634 & 24 & 0.8781 & 24 \\
\hline $\boldsymbol{P R}$ & 2.8219 & 4 & 2.8763 & 4 & 2.7704 & 3 & 2.6593 & 1 & 2.6618 & 2 \\
\hline $\boldsymbol{R} \boldsymbol{S}$ & 10.9235 & 1 & 9.2109 & 1 & 3.8770 & 1 & 2.1493 & 4 & 1.7839 & 7 \\
\hline $\boldsymbol{R} \boldsymbol{Y}$ & 2.2090 & 6 & 2.2438 & 6 & 2.1603 & 5 & 2.0597 & 5 & 2.0587 & 5 \\
\hline & & & & & & & & \\
\hline
\end{tabular}




\begin{tabular}{|c|c|c|c|c|c|c|c|c|c|c|}
\hline $\boldsymbol{S} \boldsymbol{L}$ & 0.7609 & 15 & 0.7929 & 15 & 0.9120 & 15 & 1.1599 & 18 & 1.3175 & 16 \\
\hline $\boldsymbol{S} \boldsymbol{S}$ & 1.3470 & 10 & 1.3579 & 10 & 1.2896 & 12 & 1.1871 & 16 & 1.1751 & 20 \\
\hline $\boldsymbol{T} \boldsymbol{G}$ & 0.5852 & 21 & 0.6255 & 22 & 0.7988 & 19 & 1.1799 & 17 & 1.4362 & 13 \\
\hline $\boldsymbol{T} \boldsymbol{W}$ & 0.4249 & 23 & 0.4917 & 23 & 0.7840 & 20 & 1.5015 & 11 & 2.1754 & 3 \\
\hline $\boldsymbol{V} \boldsymbol{G}$ & 0.7001 & 17 & 0.6966 & 17 & 0.6307 & 22 & 0.5184 & 27 & 0.4952 & 28 \\
\hline $\boldsymbol{V P}$ & 0.6492 & 19 & 0.6725 & 18 & 0.7499 & 21 & 0.8989 & 22 & 0.9937 & 22 \\
\hline $\boldsymbol{V} \boldsymbol{S}$ & 1.2028 & 12 & 1.2385 & 12 & 1.3374 & 11 & 1.5467 & 9 & 1.6859 & 10 \\
\hline
\end{tabular}

Table 5 Preference Ranking of Top Five Funds under Different Weights

\begin{tabular}{|c|c|c|c|c|c|}
\hline & \multicolumn{5}{|c|}{$\left(w_{1}, w_{2}\right)$} \\
\hline Rank & $(0.2,0.8)$ & $(0.3,0.7)$ & $(0.5,0.5)$ & $(0.7,0.3)$ & $(0.8,0.2)$ \\
\hline 1 & $R S$ & $R S$ & $R S$ & $P R$ & $M C$ \\
\hline 2 & $B U$ & $B U$ & $A S$ & $A S$ & $P R$ \\
\hline 3 & $A S$ & $A S$ & $P R$ & $M C$ & $T W$ \\
\hline 4 & $P R$ & $P R$ & $B U$ & $R S$ & $A S$ \\
\hline 5 & $M G$ & $M G$ & $R Y$ & $R Y$ & $R Y$ \\
\hline
\end{tabular}

Table 6 Correlation Coefficient with Three Performance Measures

\begin{tabular}{|l|r|r|r|r|r|r|r|r|}
\hline$\left(w_{1}, w_{2}\right)$ & $(.2, .8)$ & $(.3, .7)$ & $(.5, .5)$ & $(.7, .3)$ & $(.8, .2)$ & Treynor & Sharpe Jensen \\
\hline$(0.2,0.8)$ & 1 & & & & & & & \\
\hline$(0.3,0.7)$ & 0.9882 & 1 & & & & & & \\
\hline$(0.5,0.5)$ & 0.8314 & 0.8931 & 1 & & & & & \\
\hline$(0.7,0.3)$ & 0.4213 & 0.5063 & 0.7878 & 1 & & & & \\
\hline$(0.8,0.2)$ & 0.1204 & 0.1859 & 0.4532 & 0.8865 & 1 & & & \\
\hline Treynor & 0.7891 & 0.8471 & 0.9667 & 0.7329 & 0.3699 & 1 & & \\
\hline Sharpe & 0.7063 & 0.7686 & 0.9379 & 0.7774 & 0.4542 & 0.9789 & 1 & \\
\hline Jensen & 0.7799 & 0.8104 & 0.8910 & 0.6235 & 0.2917 & 0.9432 & 0.9596 & 1 \\
\hline
\end{tabular}

Next, we compare quasi-utilities with traditional performance measures. Table 6 is a matrix of the correlation coefficients between five quasi-utility values from different weights and three performance indexes. We expect the quasi-utility with the equal weight should be highly correlated with three performance indexes, because these indexes take the equal importance between return and risk. It turns out as we expected: the Treynor index has a coefficient value of 0.9667 with the quasi-utilty; the Sharpe, 0.9379; and the Jensen, 0.8910. However, correlation coefficients among five quasiutilty values are varying greatly. For instance, the coefficient between $\left(w_{1}, w_{2}\right)=$ $(0.2,0.8)$ and $\left(w_{1}, w_{2}\right)=(0.8,0.2)$ is only 0.1204 , which shows the quasi-utility function is sentive to different levels of the risk.

Figure 10 shows that when weights are tilted,in particular,toward the risk averse, the coefficients between quasi-utilty and traditional measurestakevery low values. For example, when $\left(w_{1}, w_{2}\right)=(0.8,0.2)$, Treynor index has a coefficient of 0.3699 ; the Sharpe, 0.4542; and the Jensen, 0.2917. In other words, the traditional measures do not follow the values of quasi-utility function under the risk averse situation. Hence, we can say that the traditional performance measures are not quite sensitive to the investors' risk averse attitude. 


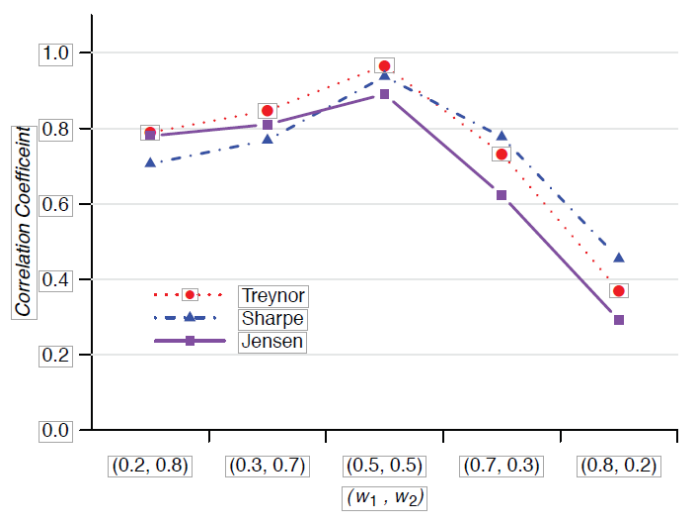

Figure 10 Correlation Coefficient between Quasi-utilities and Three Performance Indices

We further discover that preference rankings from quasi-utilities have extremely close correlations with rankings from traditional performance indexes. In fact, when $\left(w_{1}, w_{2}\right)=(0.5,0.5)$, Spearman's rank correlation coefficients are computed as: 0.9595 with Treynor; 0.9826 with Sharpe; 0.9463 with Jensen.

\section{Concluding Remarks}

Markowitz established an investment framework for the construction and selection of investment portfolios based on the maximization of expected returns and simultaneous minimization of investment risk. These two goals are basically conflicting each other. Markowitz postulated that an appropriate utility function, which was assessed by investor, could compromise two conflicting objectives.

The investor's utility is supposed to be measured by a bivariate utility function with mean and variance. But the assessment of appropriate multi-attribute utility function is so complex and intricate that the decision scientists proposed a decomposition of a multi-attribute utility assessment into a series of single-attribute assessments (Keeney and Raiffa, 1976). However, the decomposition process is still hard to proceed. Furthermore, it is difficult to understand exactly what is the utilty function of an investor. To circumvent theses difficulties, we utilized a global utility function in which the marginal rate of substitution remains unchanged throughout the feasible domain. Here we only need the global weights of risk and return. That is, $\left(w_{1}, w_{2}\right)$. These weights are incorporated into the computation of distances to the ideal and to anti-ideal portfolios. The quasi-utility function gains value when the distance from the anti-ideal increases and the distance from the ideal decreases. Hence, the maximization of the quasi-utility is a mathematical execution of the axiom of choice.

We took two cases for the performance evaluation of stock mutual funds. The results reveal that the quasi-utility faithfully reflects the investor's attitude towards the risk. In order words, investors can select portfolios that best meet his/her investment goal. We also found that the quasi-utility renders compatible ratings with the traditional performance measures. Hence, we may utilize the quasi-utility in lieu of these indexes. Furthermore, the quasi-utility approach possesses a sound choice rationale, great intuitive appeal, and a very light computation burden. However, we do not think our 
approach could compete with highly sophisticated portfolios optimization techniques. Our goal is to provide a practical portfolio evalution tool for investors and portfolio managers. The whole computation can be carried easily by the the spreadsheet.

With investment decision-making having become more complex, there is a increasing importance of other financial attributes in addition to risk and return (Aouni et al., 2018). For example, Amiri et al. (2010) evaluate portfolios only with technical attributes such as trading psychology, technical analysis, technology, trading system, capital management, trading tools, and broker. The quasi-utility can accommodate more than two attributes. We plan to study multi-criteria behavioral portfolio analyses that will include both subjective and technical attributes.

Finally, it may be useful to clarify the differences between the quasi-utility method and TOPSIS (Technique for Order Preference by Similality to Ideal Solution), which became a classic multiple attribute decision method (Yoon and Hwang, 1995; Behzadian et al., 2012; Yoon and Kim, 2017). Both methods are applicable to prioritize portfolios because both methods are formulated according to the axiom of choice. Their relationship can be viewed as that of primal and dual simplex methods in linear programing. While the TOPSIS renders an index of each portfolio that indicates the relative closeness to the ideal portfolio, the quasi-utility measures the decision maker's perceived value of each portfolio. Therefore, the quasi-utility approach, which directly matches with the principle of return maximization and risk minimization, should be more comprehensible to portfolio clients and analysts.

\section{References}

1. Amiri, M., Zandieh, M., Vahdami, B., Soltani, R., and Roshanaei, V. (2010), “An integrated eigenvector-DEA-TOPSIS methodology for portfolio risk evaluation in the FOREX spot market," Expert Systems with Applications, Vol. 37, pp. 509516.

2. Aouni, B., Doumpos, M., Perez-Gladish, B, and Steuer, R. (2018), “ On the increasing importance of multiple criteria decision aid methods for portfolio selection," Journal of the Operational Research, Vol. 69( No. 10), pp. 1525-1542.

3. Behzadian, M., Otaghsara, S. K., Yazdani, M. and Ignatius, J. (2012), "A stateof-the-art survey of TOPSIS applications," Expert Systems with Applications, Vol. 39(No. 17), pp, 13051-13069.

4. Carroll, J.D. (1972), "Individual differences and multidimensional scaling," In Shepard, R. N., Romney, A.K., and Nerlove, S., Multidimensional Scaling, New York: Seminar Press.

5. Charnes, A., Cooper, W. W., and Rhodes, E. (1978), "Measuring the efficiency of decision making units," European Journal of Operational Research, Vol.2(No. 6), pp. 429-444.

6. Coombs, C.H. (1964), Theory of Data, New York: Wiley.

7. Dember, W. N., and Earl, R.W. (1957), "Analysis of exploratory manipulatory and curiosity behaviors," Psychological Review, Vol. 64, pp. 91-96.

8. Detemple, J. (2014), "Portfolio selection: a review," Journal of Optimization Theory and Application, Vol. 161, pp. 1-21.

9. Elton, E.J., and Gruber, M.J. (1997), "Modern portfolio theory, 1950 to date," Journal of Banking \& Finance, Vol. 21(No. 11-12), pp. 1743-1759. 
10. Fabozzi, F., Gupta, F., and Markowitz, H. (2002), "The legacy of modern portfolio theory," Journal of Investing, Vol. 11(No. 3 ) pp. 7-22.

11. Fama, E.F. and French, K.R. (2004), "The capital asset pricing model: theory and evidence," Journal of Economic Perspectives, Vol. 18 (No. 3), pp. 25-46.

12. Hall, A.D. (1989), Metasystems Methodology: A New Synthesis and Unification, Oxford: Pergamon Press.

13. Huber, J. (1976), "Ideal point models of preference," Advances in Consumer Research, Vol. 8, pp. 138-142.

14. Jensen, M. (1968), "The performance mutual funds in the periods of 1945-1964," Journal of Finance, Vol. 23(No. 2), pp. 389-416.

15. Hearth, D., and Zaima, J.K. (2004), Contemporary Investment, $4{ }^{\text {th }}$ Edition, Mason, OH: Thomson.

16. Hwang, C. L., and Yoon, K. (1981), Multiple Attribute Decision Making: Methods and Applications, Berlin, Germany: Springer-Verlag.

17. Hodges, S. (1998), "A generalization of the Sharpe ratio and its application to valuation bounds and risk measures," working paper, Financial Options Research Center, University of Warwick.

18. Kalayci, C.B., Ertenlice, O., and Akbay, M.A. (2019), “A comprehensive review of deterministic models and applications for mean-variance portfolio optimization”, Expert Systems with Applications, Vol. 125(No. 1), pp. 345-368.

19. Kamakura, W., and Srivastava, R. (1986), "An ideal point probabilistic choice model for heterogeneous preferences," MarketingSciences, Vol. 5 (Summer), pp.199-218.

20. Keeney, R. L., and Raiffa, H. (1976), Decisions with Multiple Objectives: Preferences and Value Tradeoffs, New York: Wiley

21. Kolm, P.N., Tutuncu, R., and Fabozzi, F.J. (2014), "60 years of portfolio optimization: practical challenges and current trends," European Journal of Operational Research, Vol. 234(No. 2), pp. 356-371.

22. Liu, W., Zhou, Z., Liu, D., and Xiao, H. (2015), "Estimation of portfolio efficiency via DEA," Omega, Vol. 52, pp. 107-118.

23. Mackay, D.B, Easley, R.F., and Zinnes, J.L. (1995), "A single ideal point model for market structure analysis," Journal of Marketing Research, Vol. 32, pp.433443.

24. Mangram, M.E. (2013), "A simplified perspective of the Markowitz portfolio theory," Global Journal of Business Research, Vol. 7(No. 1), pp. 59-70.

25. Markowitz, H. (1952), "Portfolio selection," Journal of Finance, Vol. 7(No. 1), pp. 77-91.

26. Markowitz, H. (1959), Portfolio Selection, New Haven: Yale University Press.

27. Markowitz, H. (2014), "Mean-variance approximations to expected utility," European Journal of Operational Research, Vol. 234, pp. 346-355.

28. Michalowski, W. (1988), "Use of the displaced worst compromise in interactive multiobjective programming," IEEE Transactions on System, Man, Cybernetics, Vol. 18(No. 3), pp.472-477.

29. Michalowski, W., and Szapiro, T. (1989), “A procedure for worst outcomes displacement in multi criteria decision making," Computers and Operations Research, Vol. 16(No. 3), pp. 195-206. 
30. Michaud, R.O. (1989), "The Markowitz optimization enigma: is optimization optimal?," Financial Analysis Journal, Vol. 45(No. 1), pp. 31-42.

31. Reilly, F. K., and Brown, K.C. (2006), Investment Analysis and Portfolio Management, 8 th Edition, Mason, $\mathrm{OH}$ : Thomson.

32. Sharpe, W. (1964), "Capital asset prices: a theory of market equilibrium under conditions of risk," Journal of Finance, Vol. 19 (No. 3), pp. 425-442.

33. Sharpe, W. (1966), “Mutual fund performance," Journal of Business, Vol. 39(No. 1, Part 2), pp. 119-138.

34. Shen, W. F., Zhang, D.Q.,Liu, W.B., and Yang, G.L. (2016), "Increasing discrimination by utilizing distnances to anti-efficient DEA frontiers, Computers and Operations Research, Vol. 75, pp. 163-173.

35. Treynor, J. (1965), "How to rate management investment funds," Harvard Business Review, Vol. 43(No. 1), pp.63-75.

36. Yoon, K.P., and Hwang, C.L. (1995), Multiple Attribute Decision Making: An Introduction, Thousand Oaks, CA: Sage Publication.

37. Yoon, K.P., and Kim, W.K. (2017), “ The behavioral TOPSIS,” Expert Systems with Applications, Vol. 89(No. 15), pp.266-272.

38. Yu, P.L. (1973), “A class of solutions for group decision problems," Mangement Sciences, Vol. 19(No. 8), pp. 936-946.

39. Zhang, Y., Li, X., and Guo, S. (2018), "Portfolio selection problems with Markowitz's mean-variance framework: a review of literature," Fuzzy Optoimization and Decision Making, Vol. 17, pp. 125-158.

40. Zakamouline, V., and Koekebakker, S. (2009), "Portfolio performance evaluation with generalized Sharpe ratios: beyond the mean and variance," Journal of Banking and Finance, Vol. 33(No. 7), pp. 1242-1254.

41. Zeleny, M. (1982), Multiple Criteria Decision Making, New York: McGraw-Hill.

\section{About Our Authors}

K. Paul Yoon is Professor of Decision Sciences at Fairleigh Dickinson University. His B.S. degree is from Seoul National University, Korea, and his M.S. and Ph.D. degrees in Indistrial Engineering from Kansas State University. His research topics mainly focus on the efficiency of service, operation and finance systems. He is a cocreator of TOPSIS, a cassical method in multiple attribute decsion making.

Mohammad Sedaghat is a Professor in the Department of Marketing, Information Systems and Decision Sciences at Fairleigh Dickinson University. He obtained his Ph.D. in Operations Research from Polytechnic University, New York. His research interests include Queuing theory and stochastic processes.

Gyutai Kim is Professor of Industrial Engineering at Chosun University, Korea. He received his a BSIE degree from Sung Kyun Kwan University, Korea, an MSIE degree from Fairleigh Dickinson University, and a $\mathrm{Ph}$. D. degree from Auburn University. His research areas of interest are an application of real options pricing theories and the Kelly Criterion to an economic decision analysis. He is currently working on the multiple real options pricing model with a Bayesian theory and a survey on capital budgeting practices performed by the firms in Korea. 